\title{
ABORDAGENS EPISTEMOLÓGICAS DA DIVERSIDADE E SUJEITOS REPRESENTADOS EM PESQUISAS EDUCACIONAIS
}

EPISTEMOLOGICAL APPROACHES OF DIVERSITY AND SUBJECTS REPRESENTED IN EDUCATIONAL RESEARCH

ENFOQUES EPISTEMOLÓGICOS DE DIVERSIDAD Y SUJETOS REPRESENTADOS EN LA INVESTIGACIÓN EDUCATIVA

SANTOS, Amarildo Inácio dos ${ }^{1}$

\section{RESUMO}

O artigo apresenta a análise de artigos publicados em 20 periódicos para responder: quais linhas epistemológicas sustêm debates sobre diversidade na educação e quais sujeitos da diversidade são representados? Com isso, objetivou-se mapear linhas epistemológicas sobre pesquisas educacionais que mobilizaram o conceito de 'diversidade' e 'sujeitos da diversidade'. Trata-se de uma pesquisa bibliográfica e de análise de conteúdo. Concluiu-se que predominam as teorias pós-críticas nas investigações entre educação e diversidade. A maioria dos artigos discute formas de combater as violências e exclusões, mas a diversidade é pouco problematizada como produção identitária que produz efeitos de poder.

Palavras-chave: Abordagem epistemológica. Currículo. Diversidade. Levantamento bibliográfico.

\section{ABSTRACT}

The article presents articles published in 20 journals in order to answer: which epistemological lines support debates about diversity in education and which diversity subjects are represented the aimed was to map epistemological lines of educational research articles that will give movement to the concept of diversity and diversity subjects. The methodology used is bibliographic research and content analysis. Most articles discuss ways to combat violence and exclusion, but diversity is hardly problematized as an identity production that produces power effects.

Keywords: Bibliographic research. Educational Curriculum. Diversity. Epistemological approach.

\section{RESUMEN}

El artículo presenta el análisis de artículos publicados en 20 periódicos para responder: ¿cuáles líneas epistemológicas sostienen debates sobre diversidad en la educación y cuales sujetos de diversidad son representados? Con eso se puso como objetivo mapear líneas epistemológicas sobre investigaciones educacionales que movilizarán el concepto de "diversidad" y "sujetos de la diversidad". Se trata de una investigación bibliográfica y de análisis de contenido. La mayoría de los artículos discute formas de combatir las violencias y exclusiones, pero la diversidad es poco problematizada como producción de identidad que produce efectos de poder.

Palabras clave: Currículo. Diversidad. Enfoque epistemológico. Levantamiento bibliográfico.

\footnotetext{
${ }^{1}$ Universidade Federal da Bahia - UFBA - Salvador - Bahia - Brasil.
} 


\section{INTRODUÇÃO}

Os debates sobre diversidade e educação começaram a proliferar na educação brasileira a partir da segunda metade da década de 1990 (CARREIRA, 2019). Há uma coincidência entre a irrupção desses debates e a reabertura democrática iniciada com o fim da ditadura civil-militar. O ciclo de ampliação do acesso à escolarização, iniciado nos anos de 1970 (GONÇALVES, 2011), cresceu nas décadas de 1980 e 1990 e também influenciou o surgimento dessas discussões chamando a atenção para a incapacidade de os sistemas de ensino administrarem contextos de crescente diversidade cultural e identitária (LÓPEZ, 2012). A massificação da educação coincidiu, ainda, com a emergência de movimentos sociais negros, feministas, indígenas, homossexuais que opuseram resistências ao regime militar no final da década de 1970 (ABRAMOWICZ; DA CRUZ; RODRIGUES, 2011). Neste período a democracia brasileira começou a se tornar uma realidade cercada de muita expectativa e coroada pela promulgação da Constituição Federal, em 1988. O documento contemplou anseios democráticos de muitos brasileiros e trouxe a promessa de uma sociedade justa e igualitária. Inspirados pelas possibilidades que a democracia anunciava os integrantes da Assembleia Nacional Constituinte de 1987 decidiram, entre outras coisas, contemplar demandas históricas de movimentos sociais salvaguardando direitos e garantias fundamentais, como o previsto no artigo quinto: "Todos são iguais perante a lei, sem distinção de qualquer natureza [...]" (BRASIL, 1988). O direito social à educação também foi assegurado em seu artigo sexto. "São direitos sociais a educação [...]" (BRASIL, 1988). Essas mudanças estão ainda relacionadas às prescrições da Declaração Universal dos Direitos humanos proclamada pela Assembleia Geral das Nações Unidas em Paris em 1948, à qual o Brasil aderiu na mesma data.

A massificação e obrigatoriedade da educação, as lutas de movimentos sociais, o resgate do apreço pelos direitos humanos e os novos princípios constitucionais democráticos produziram efeitos na educação, no que tange à diversidade. A título de exemplo foi promulgada em 1996, em alinhamento aos princípios da Constituição Federal de 1988, a Lei de Diretrizes e Bases da Educação Nacional (LDBEN), Lei $n^{\circ}$ 9.394. O documento estabelece em seu artigo terceiro os princípios a partir dos quais o ensino será ministrado. Entre os princípios estão: igualdade de condições de acesso e permanência, apreço à tolerância e consideração com a diversidade étnica. A lei determina, ainda, os moldes de diferentes modalidades de ensino, entre elas, a Educação de Jovens e Adultos (EJA) e a Educação Especial.

Em 2003 a Lei $n^{\circ}$ 10.639/2003 alterou a LDBEN introduzindo a obrigatoriedade do estudo da história e cultura afro-brasileira. Em 2008 a Lei 11.645/2008 inseriu o artigo 26-A na LDBEN instaurando a obrigatoriedade do estudo da história e cultura indígenas. Desde então, ambos são componentes curriculares obrigatórios no Ensino Fundamental e Médio. Essas alterações foram tentativas de contemplar a diversidade étnica que povoa as escolas nas distintas regiões do Brasil. $O$ princípio da isonomia, ao determinar que todos são iguais perante a lei (BRASIL, 1988), impõe mudanças na educação. A escola se vê frente a necessidade de incluir sujeitos que por muito tempo tiveram seu direito à educação tolhido em função de suas singularidades, marcadores sociais marginalizados e marginalizantes. Diante das determinações legais que instauraram a obrigatoriedade 
da escolarização a escola precisou aprender a administrar estudantes diversos do modelo por ela idealizado e desejado, o "estudante urbano, branco, de classe média ou alta, de família 'bem constituída' e 'moral impecável”' (LÓPEZ, 2012, p. 878, tradução minha). Isso produziu um descompasso entre os sujeitos desejados pela escola e os que efetivamente compõem seu cotidiano.

O novo cenário fomentou debates e influenciou a produção de políticas públicas, leis, resoluções, decretos, diretrizes, normativas, programas, regulamentos, parâmetros, pareceres, ações, etc. Esses documentos delinearam os contornos de currículos alinhados ao novo ethos democrático no qual a inclusão da diversidade tornou-se um imperativo. Diante do desafio de pautar o ensino a partir de princípios democráticos garantidores do acesso e da permanência de todos, sem distinções de qualquer natureza (BRASIL, 1988), ficou evidente que a escola e os professores/as não estavam preparados para lidar com tamanha complexidade. Isso evidenciou lacunas nos currículos de formação docente que passaram a ser discutidos, repensados e/ou alterados. Para fazer frente a isso uma das medidas adotadas foi a elaboração de políticas de formação continuada e documentos orientadores para subsidiar professores/as tornando-os mais aptos a desempenhar a docência nos moldes do novo paradigma.

$\mathrm{Na}$ esteira destas demandas foram criados os Parâmetros Curriculares Nacionais - PCN (GONÇALVES, 2011). Ao apresentar os Temas Transversais os PCN propõem que as temáticas “ Ética, Meio Ambiente, Pluralidade Cultural, Saúde e Orientação Sexual" (BRASIL, 1997) povoem a prática docente de professores/as no Ensino Fundamental. O documento explicita os critérios de seleção dos temas acima elencados. Um deles é a urgência social, "questões graves, que se apresentam como obstáculos para a concretização da plenitude da cidadania, afrontando a dignidade das pessoas e deteriorando sua qualidade de vida" (BRASIL, 1997, p. 25-26). Urge garantir que ninguém tenha seu direito à educação cerceado. A dignidade mencionada nos PCN é um dos princípios fundamentais previstos na Constituição o que sinaliza a influência direta do documento no redesenho da educação brasileira a partir de 1988. O desafio proposto pelos PCN, segundo Abramowicz, Da Cruz e Rodrigues (2011), é pensar estratégias educacionais que incluam a diversidade sem descaracterizá-la, mas colocando as múltiplas expressões em diálogo. "Cabe destacar as orientações dos Parâmetros Curriculares Nacionais como uma política educacional dirigida para uma educação na perspectiva da diversidade" (ABRAMOWICZ; DA CRUZ; RODRIGUES, 2011, p. 90).

A complexidade do tema insuflou a produção científica que passou a investigar a diversidade, seus efeitos, limites e tensões, contribuindo para a produção de um novo cenário da educação. Muitas pesquisas em interface com a diversidade em suas múltiplas linhas epistemológicas e aspectos, religiosa, cultural, étnica, geracional, sexual, social, etc, subsidiaram e embasaram políticas públicas inclusivas e ações afirmativas visando assegurar garantias constitucionais. Diante disso pretendo compor um retrato que permita compreender, em linhas gerais, como está a produção científica em torno da diversidade na educação atualmente. "[...] o estudo epistemológico da pesquisa nas ciências da ação preocupa-se com as principais tendências teórico-filosóficas, opções paradigmáticas ou modos diversos de interpretar a realidade (DA SILVA; GAMBOA, 2014, p. 54). Conhecer as filiações epistemológicas utilizadas permite inferir direcionamentos que a educação tem tomado e compreender estratégias que tem desenvolvido para assegurar o direito social à educação. 
Frente ao exposto e visando orientar o estudo formulei a questão: quais linhas epistemológicas sustêm debates sobre diversidade na educação e quais sujeitos da diversidade são representados? O objetivo foi mapear linhas epistemológicas em artigos oriundos de pesquisas educacionais que mobilizaram o conceito de diversidade e sujeitos da diversidade.

\section{CAMINHOS METODOLÓGICOS}

A metodologia foi pesquisa bibliográfica, "desenvolvida com base em material já elaborado, constituído principalmente de livros e artigos científicos" (GIL, 2002, p. 44). Neste caso, selecionei artigos publicados entre 2014 e 2019. Este recorte temporal é feito porque queria saber o que se está dizendo sobre educação e diversidade na contemporaneidade. Fiz a busca em 20 periódicos da área da educação que selecionei na Plataforma Sucupira da Coordenação de Aperfeiçoamento de Pessoal de Nível Superior (CAPES). Os critérios de seleção dos periódicos foram: pertencimento à área de avaliação da educação e classificação nos estratos A1 e A2 do Qualis da CAPES no quadriênio 20132016. Das 20 revistas, dez estão classificadas como A1 e dez como A2. Levei em conta esse critério porque os estratos A1 e A2 indicam maior qualidade e impacto dos trabalhos.

No que se refere aos procedimentos analíticos optei pela análise de conteúdo de Bardin (1977) que a descreve em três polos cronológicos: pré-análise, exploração do material, tratamento dos resultados, inferência e interpretação. Selecionados os periódicos iniciei o levantamento de publicações. Busquei pelo descritor "diversidade" em títulos, resumos e palavras-chave e selecionei todos os que encontrei. Este levantamento inicial resultou em 29 trabalhos. Em seguida realizei a préanálise que tem três objetivos: selecionar os documentos a serem analisados, formular hipóteses e objetivos e elaborar indicadores que fundamentarão a interpretação final (BARDIN, 1977). A autora salienta que não há ordem cronológica de execução entre estes três objetivos, pois estão imbricados. Assim, a seleção dos documentos pode depender dos objetivos formulados ou os documentos selecionados podem determiná-los. Do mesmo modo, os indicadores podem servir de base para a formulação de hipóteses ou ser construídos a partir das hipóteses pré-formuladas pelo pesquisador.

A pré-análise possui algumas etapas e a primeira é a leitura flutuante que "[...] consiste em estabelecer contato com os documentos a analisar e em conhecer o texto deixando-se invadir por impressões e orientações" (BARDIN, 1977, p. 96). Esta leitura é importante, pois permite extrair impressões que fornecem um panorama inicial sobre o que dizem as publicações possibilitando efetuar a escolha dos documentos a serem analisados e reconfigurar o corpus que "[...] é o conjunto dos documentos tidos em conta para serem submetidos aos procedimentos analíticos" (BARDIN, 1977, p. 96). Esta autora escreve que a escolha dos documentos é feita segundo diferentes regras que ela elenca e descreve. Neste trabalho observei a regra da pertinência, segundo a qual "os documentos retidos devem ser adequados, enquanto fonte de informação, de modo a corresponderem ao objetivo que suscita a análise" (BARDIN, 1977, p. 97). O objetivo que suscitou a análise foi mapear linhas epistemológicas em artigos oriundos de pesquisas educacionais que mobilizaram o conceito de diversidade e sujeitos da diversidade. Assim, a seleção dos documentos foi determinada pelo objetivo, 
uma das possibilidades descritas por Bardin (1977), e possibilitou reestruturar o corpus chegando a 25 artigos.

Da leitura flutuante inferi indicadores que servem para fundamentar a interpretação final (BARDIN, 1977). Os indicadores sugerem que as pesquisas atuais sobre diversidade na educação estão implicadas com as temáticas: "Formação docente na perspectiva da diversidade" (10); "Políticas públicas e diversidade" (4); "Diversidade e violências" (4); "Currículos para a diversidade" (2); " Legislação e diversidade" (2); "Afirmação identitária" (1); "Diversidade e desempenho escolar" (1) e " Problematização da diversidade" (1). A seguir falarei brevemente sobre elas.

\section{FORMAÇÃO DOCENTE NA PERSPECTIVA DA DIVERSIDADE}

Dez artigos relacionam a diversidade com a necessidade de formação docente, sinalizando uma preocupação com a formação de professores/as aptos a administrar, como escreve López (2012), contextos escolares de crescente diversidade cultural e identitária. Isto está alinhado a diversos documentos da educação que postulam uma educação na diversidade. Mapeei as linhas epistemológicas:

1. Interculturalidade e Multiculturalismo: Vargas e Sanhueza (2018); Abu-El-Haj e Fialho (2019).

2. Estudos de Gênero: Souza, Da Silva e Santos (2016); Arévalo (2017) e Furlan e Müller (2015).

3. Estudos Étnicos e Raciais: Sousa e Lima (2017) e Mwewa et al. (2017).

4. Teoria Crítica: Costa, Dalla Corte e Da Silva. (2018); Pereira; Damasceno (2017) e Sant' Anna e Marques (2015).

Salvo especificidades de cada artigo, os trabalhos apresentam, como preocupação central e eixo de argumentação, a necessidade de formação docente pautada na perspectiva da diversidade. Os sujeitos da diversidade representados são: negros, indígenas, pessoas com deficiências, campesinos e sujeitos que compõem a diversidade sexual. Inferi uma crença generalizada de que a formação docente pautada na perspectiva da diversidade pode subsidiar professores/as com saberes e conhecimentos, ainda ausentes ou pouco presentes nos currículos oficiais dos cursos de formação superior, tornando-os mais aptos a gerir a diversidade que povoa as escolas. Esta formação contribuiria para a superação da matriz monocultural, ainda vigente na educação brasileira e na América Latina de modo geral, minimizando exclusões e violências e garantindo o direito à cidadania e à educação para todos, conforme determina a Constituição Federal de 1988.

\section{POLÍTICAS PÚBLICAS E DIVERSIDADE}

Quatro artigos apostam na criação de políticas públicas, avaliam ou analisam políticas públicas para a diversidade. As linhas epistemológicas mobilizadas nestes trabalhos são:

1. Estudos Culturais: Oliveira Júnior e Maio (2015).

2. Pós-estruturalismo: Valderrama e Melis (2019).

3. Estudos de Gênero: Vianna (2015). 
4. Teoria Crítica: Carreira (2019).

À exceção de Carreira (2019), que realiza uma análise da execução orçamentária das políticas públicas voltadas às diferentes expressões da diversidade durante os governos Lula e Dilma, os artigos de Oliveira Júnior e Maio (2015); Vianna (2015) e Valderrama e Melis (2019), apesar de utilizarem diferentes abordagens epistemológicas, versam sobre políticas públicas para a diversidade sexual e de gênero na escola. Os sujeitos da diversidade representados são os que compõe a diversidade sexual, negros, quilombolas, indígenas, jovens e adultos não escolarizados na idade certa e campesinos.

Inferi que há um consenso entre estes últimos autores de que o tema da diversidade sexual e de gênero ainda é lacunar na educação no Brasil e em países da América Latina. Em linhas gerais, os autores defendem que o tema seja debatido para assegurar direitos sociais destes sujeitos e evitar que tenham prejuízos em seu desenvolvimento pessoal e escolar.

\section{DIVERSIDADE E VIOLÊNCIAS}

Quatro artigos discutem a diversidade em interface com violências na escola. Os trabalhos de Graupe e Lins (2018); Oliveira Júnior e Maio (2019) e Méndez-Tapia (2015) abordam a temática das violências aos sujeitos da diversidade sexual, diferindo em relação à ancoragem epistemológica. Já o artigo de Dias e Souza Neto (2019) discute violências a indivíduos de nacionalidade diversa. Neste caso, estudantes bolivianos e/ou descendentes de bolivianos que vivem em São Paulo e estudam em turmas de $8^{\circ}$ e $9^{\circ}$ anos em uma escola pública da capital paulistana. Mapeei 3 linhas epistemológicas:

1. Multiculturalismo: Dias e Souza Neto (2019).

2. Teoria Queer. Graupe e Lins (2018).

3. Estudos de Gênero: Oliveira Júnior e Maio (2019) e Méndez-Tapia (2015).

Pude inferir que em contextos escolares, abrangendo Educação Básica e Ensino Superior, as violências são majoritariamente destinadas a sujeitos desviantes de normas reproduzidas nos (e pelos) currículos. Além disso, percebi que há um incômodo com o silenciamento da escola e da universidade diante de práticas violentas endereçadas a sujeitos não-normativos. As normas se pretendem fixas e demarcam territórios a partir dos quais produzem seus desvios e os organizam hierarquicamente deslocando-os a um lugar socialmente desprestigiado convertendo-os em endereços de violências físicas e simbólicas. As normas que mapeei nos trabalhos são relativas a gênero, sexualidade e nacionalidade que produzem suas respectivas desvianças, alvos de violências na escola.

\section{CURRÍCULOS PARA A DIVERSIDADE}

Trujillo (2015) e Feldmann e Silva (2018) analisam contextos bastante distintos pensando currículos específicos que atendam às demandas dos sujeitos envolvidos nos processos educativos.

Amparando-se na Teoria Queer Trujillo (2015) busca pensar um "currículo queer" que contemple a diversidade sexual na Espanha. A partir dos estudos de Guacira Lopes Louro, Trujillo (2015) argumenta que um currículo queer pode oferecer resistência à heteronormatividade curricular que produz exclusão a partir de marcadores sociais de gênero e sexualidade. 
Feldmann e Silva (2018) tomam a Pedagogia Crítica como linha epistemológica para pensar um currículo voltado a sujeitos não escolarizados na idade certa que vivem em um contexto específico, a tríplice fronteira Brasil-Peru-Colômbia, localizada no Sudoeste do Amazonas. As especificidades do contexto demandam, segundo os autores, atenção às necessidades destes sujeitos para garantir-lhes uma educação emancipadora.

Os trabalhos elegem linhas epistemológicas distintas para embasar suas argumentações. Todavia, a preocupação que os subjaz é a mesma: garantir o direito social à educação de sujeitos historicamente excluídos dos processos educativos em razão de suas singularidades não contempladas pelos currículos escolares tradicionais. Os sujeitos representados são os que compõem a diversidade de gênero e sexualidade e jovens e adultos não escolarizados na idade certa.

\section{LEGISLAÇÃO E DIVERSIDADE}

Dois artigos versam sobre legislações criadas para contemplar sujeitos da diversidade. Russo e Paladino (2016) elegem a Decolonialidade e a Interculturalidade crítica para investigar a implementação da Lei n. 11.645/2008 que instaura a obrigatoriedade do ensino da história e cultura indígena na Educação Básica em escolas das Redes Municipal e Estadual do Rio de Janeiro.

Gomes (2017) mobiliza os Estudos Étnicos e Raciais ao aplicar, em sua prática docente, as determinações da Lei n. 10.639/03 que instituiu a obrigatoriedade do ensino da história e cultura africanas e afro-brasileiras. $\mathrm{O}$ autor investigou o uso do estudo das divindades africanas relacionandoas à mitologia grega em uma escola pública no Rio Grande do Sul.

Em ambos os casos percebi uma postura de vigilância à aplicabilidade (ou não) das legislações mencionadas e os impactos disso no cotidiano escolar. Percebi uma crença na afirmação cultural e identitária como forma de superação de exclusões advindas de marcadores sociais de raça e etnia.

\section{AFIRMAÇÃO IDENTITÁRIA}

Teixeira (2018) reflete sobre o ensino do que nomeia "questões controversas" analisando seus desafios na educação. Ancorado na Interculturalidade Crítica o autor argumenta que em função da existência de múltiplas visões de mundo, religiões, gêneros, orientações sexuais e raças nas escolas, o ensino de "questões controversas" tornou-se um território disputado. Reflete sobre o avanço de pautas conservadoras como o Escola Sem Partido discutindo os riscos disso para a educação democrática. Apresenta a afirmação identitária como possibilidade de enfrentamento e superação do conservadorismo. Entende que dar visibilidade a diferentes grupos sociais e distintas formas de conhecimento e visões de mundo, contemplando a pluralidade cultural que povoa as escolas colocando diferentes expressões em diálogo, pode promover conhecimento e minimizar preconceitos e violências. Conclui que é necessário "estimular o desenvolvimento de estratégias pedagógicas e projetos políticopedagógicos que reconheçam identidades e promovam diferentes formas de conhecimento, questionando poderes hegemônicos em nossa sociedade" (TEIXEIRA, 2018, p. 512). Para o autor a resistência se faz pela afirmação das identidades socialmente marginalizadas. 


\section{DIVERSIDADE E DESEMPENHO ESCOLAR}

Silva e Paes (2014) desenvolveram uma pesquisa ancorada na Pedagogia Crítica em uma turma de terceiro ano do Ensino Fundamental I, com 45 crianças, em uma escola da Rede Municipal de Garanhuns - PE. Segundo os autores, as crianças provêm de famílias socialmente excluídas. Buscaram identificar diferenças socioculturais que constituem ou podem constituir obstáculos para a aprendizagem em função de o currículo privilegiar uma cultura em detrimento da multiplicidade cultural. Identificaram dois grupos de crianças: o que apresenta baixo desempenho escolar e o que apresenta melhor desempenho. O grupo com desempenho inferior é atravessado por situações socioculturais que diferem da cultura privilegiada pelo currículo, o que obstaculiza a aprendizagem. Os pesquisadores identificaram, ainda, relações interpessoais discriminatórias, por parte da professora, que reforçam nas crianças a sensação de que são incapazes. Também identificaram problemas de natureza didática que dificultam a aprendizagem. Concluem que o baixo e o bom desempenho escolar são produzidos no mesmo espaço a partir da origem sociocultural das crianças que é utilizada para marcá-las como capazes ou incapazes.

\section{PROBLEMATIZAÇÃO DA DIVERSIDADE}

Bentes e Hayashi (2016) analisaram as mudanças no Instituto Nacional de Surdos (INES) desde sua fundação (1857) até o início do século XXI. A análise recaiu sobre a educação especial e tomou os surdos como sujeitos da diversidade. O estudo utilizou fontes documentais como legislação, documentos historiográficos e a literatura sobre educação de surdos. A pesquisa ancorou-se no Pósestruturalismo para questionar metanarrativas que instauram verdades sobre a surdez produzindo discursivamente o sujeito surdo e o que se pensa como educação para ele. Concluem que os discursos de diversidade predominam na área da educação especial produzindo a inclusão de surdos na educação de ouvintes. Os autores argumentam que essa inclusão ocorre sob o discurso de reconhecimento das diferenças que escamoteia processos de normalização e perpetua a lógica hierárquica entre norma e anomia. Neste sentido os autores escrevem que "As principais características da diversidade são a ocultação do processo de dominação ou violência, com um discurso de reconhecimento e valorização das diferenças entre as pessoas, suspendendo a atitude anterior de normalização dos indivíduos" (BENTES; HAYASHI, 2016, p. 854). Defendem pensar a condição do surdo pelo viés da alteridade em vez da diversidade que inclui os diversos na lógica normativa produzindo exclusão na inclusão.

\section{EDUCAÇÃO E DIVERSIDADE: O QUE AS PUBLICAÇÕES ATUAIS INDICAM?}

Segundo Bardin (1977), após a exploração do corpus inicia-se o tratamento dos resultados. Nesta fase "O analista, tendo à sua disposição resultados significativos e fiéis, pode então propor inferências e adiantar interpretações a propósito dos objetivos previstos, ou que digam respeito a 
outras descobertas inesperadas" (BARDIN, 1977, p. 101). A exploração do material selecionado permitiu mapear as linhas epistemológicas que sustêm as publicações analisadas alcançando um dos objetivos.

São elas: Interculturalidade (2), Multiculturalismo (3), Estudos de Gênero (6), Estudos Étnicos e Raciais (3), Teoria Crítica (4), Estudos Culturais (1), Pós-estruturalismo (2), Teoria Queer (2), Decolonialidade (1), Interculturalidade Crítica (2) e Pedagogia Crítica (2).

A análise dos trabalhos indica uma predominância das teorias pós-críticas para investigar a diversidade na educação. Essas pesquisas recebem "[...] influências da chamada 'filosofia da diferença' , do pós-estruturalismo, do pós-modernismo, da teoria queer, dos estudos feministas e de gênero, dos estudos multiculturalistas, pós-colonialistas, étnicos, ecológicos etc.". (PARAíSO, 2004, p. 284). Tais perspectivas constituem as distintas linhas epistemológicas que fundamentam a maioria dos trabalhos lidos e analisados. A análise de Paraíso (2004) considerou pesquisas e ensaios publicados em encontros anuais da Anped e em livros que tratam da educação na perspectiva pós-crítica. Em suas buscas a autora só encontrou trabalhos que mobilizaram as teorias pós-críticas a partir de 1993 e estendeu suas buscas até 2003. Seu estudo permite observar ao menos duas alterações significativas na área da pesquisa educacional no Brasil que dialogam com os resultados deste trabalho. A primeira é o crescimento do interesse de pesquisadores por questões até então relegadas às margens dos processos educacionais e pouco exploradas, como questões raciais, de gênero e sexualidade. Esse crescente interesse resulta, em parte, das determinações legais engendradas pela Constituição Federal de 1988 que produziram efeitos jurídicos e determinaram a reelaboração de documentos oficiais da educação. Esses documentos reverberaram em planejamentos curriculares de escolas, em práticas pedagógicas, na formação docente e na educação como um todo.

A outra alteração significativa apontada por Paraíso (2004) e corroborada pelos resultados deste trabalho, diz respeito à perda da hegemonia discursiva das Teorias Críticas. As linhas epistemológicas reunidas sob o título de pesquisas pós-críticas ampliam os debates e "[...] realizam, no campo educacional brasileiro, substituições, rupturas e mudanças de ênfases em relação às pesquisas críticas (PARAíSO, 2004, p. 284). O surgimento de outras perspectivas de pensamento instaurou disputas discursivas que favoreceram a proliferação de discursos e sentidos enriquecendo os debates de modo que "Aparece, no terreno educacional, uma multiplicidade de pesquisas e trabalhos que pensam a educação, a pedagogia, o currículo e outras práticas educativas de modo diferente do que até então vinha sendo pensado" (PARAíSO, 2004, p. 286). Essa mudança de abordagem nas pesquisas, também observada neste estudo, sinaliza um recalibramento dos focos de interesse que estão alinhados às exigências contemporâneas de um ethos democrático instaurado no Brasil pósditadura civil-militar. Questões antes pouco debatidas, como inclusão de pessoas com deficiências, se tornaram cada vez mais frequentes e abrangentes, haja vista que as escolas atualmente precisam incluir a todos, indistintamente (BRASIL, 1988). Diante dessas mudanças inúmeras perguntas, muitas das quais se tornaram pesquisas em nível de pós-graduação stricto sensu, passaram a exigir ferramentas teórico-metodológicas e analíticas distintas das já existentes e as teorias pós-críticas "[...] utilizam uma série de ferramentas conceituais, de operações analíticas e de processos investigativos que as destacam tanto das teorias tradicionais como das teorias críticas que as precederam" 
(PARAíSO, 2004, p. 284). Essas ferramentas abrangeram questões sobre as quais as Teorias Tradicionais e Críticas até então não se debruçavam satisfatoriamente.

A segunda inferência que fiz foi que 24 dos 25 artigos, salvo singularidades de filiação epistemológica, se sustentam sobre o primado da identidade. De modo geral as preocupações orbitam em torno de como incluir os diversos; como formar professores/as aptos a lidar pedagogicamente com esses sujeitos; como diminuir violências; análise de políticas públicas e ações afirmativas direcionadas ao acesso e permanência dos sujeitos diversos; investigação do desempenho escolar dos estudantes marcados como diversos; currículos específicos que contemplem esses sujeitos; argumentação em favor da afirmação identitária das diversidades e análise da observância (ou não) de legislações voltadas à reparar exclusões históricas de sujeitos diversos e seus efeitos na escola. A exceção é o artigo de Bentes e Hayashi (2016) que, em vez de afirmar, interroga a identidade surda a partir de uma perspectiva pós-estruturalista. Inferi que há uma crença generalizada na afirmação de identidades marginalizadas para superar efeitos de poder que redundam em exclusão e violências.

Por fim, os sujeitos da diversidade representados são: campesinos, jovens e adultos não escolarizados na idade certa, indígenas, negros, sujeitos que compõem a diversidade sexual e de gênero, estrangeiros, pessoas com deficiências e diversidade sociocultural. Esses são os sujeitos a ser incluídos. É em torno deles e para eles que se elaboram políticas públicas e ações afirmativas. O conjunto dos opostos de cada identidade acima elencada resulta no modelo desejado pelo currículo que se institui como maioria. "O que define a maioria é um modelo ao qual é preciso estar conforme: por exemplo, o europeu médio adulto macho habitante das cidades..." (DELEUZE, 2013, p. 218). E a partir da leitura dos artigos acrescento: branco/a, escolarizado/a, sem deficiências, brasileiro/a e cristã/o. Cada identidade normalizada possui seu correlato de desvio que agencia um binarismo. É ao conjunto desses desvios das referências que nomeamos diversidade e "[...] se um sujeito, um comportamento, uma conduta ou uma prática não são os referentes, eles só podem ser avaliados de forma negativa" (PARAÍSO, 2010, p. 145). Por isso as identidades produzidas como desviantes se tornam endereço de múltiplas violências, o que demanda do Estado respostas que se materializam em políticas públicas e demais ações que visam à inclusão. A norma produz o anômico, o exclui e então o inclui. Porém, no processo de inclusão, as posições hierárquicas inerentes a cada um são reforçadas, pois a inclusão ocorre no universo inerente às normas que seguem intactas.

\section{CONSIDERAÇÕES FINAIS}

Busquei mapear linhas epistemológicas que sustentam pesquisas sobre educação e diversidade, bem como, sujeitos da diversidade representados atualmente. A análise me permite argumentar que sujeito da diversidade é aquele que diverge de alguma norma naturalizada a qual deveria se reportar, mas da qual desvia. Este desvio instaura um binarismo reduzindo a multiplicidade a dois polos dicotômicos que se anulam e se afirmam mutuamente. Deleuze e Guattari (2012) nomeiam isso de agenciamentos binários e escrevem que são produzidos por máquinas binárias distintas: "Máquinas binárias de classes sociais, de sexos, homem-mulher, de idades, criança-adulto, de raças, branco-negro, de setores, público-privado, de subjetivações, em nossa casa-fora de casa" 
(DELEUZE; PARNET, 1998, p. 150). Essas máquinas são semióticas que ordenam a normalidade e detectam desvios desempenhando função de binarização e convertendo diferença pura (DELEUZE, 2018) em diversidade. Da análise dos artigos inferi os binarismos: urbano - rural; escolarizado na idade certa - não escolarizado na idade certa; brancos - indígenas; brancos - negros; heterossexual - não heterossexual (compreendida a pluralidade de expressões da sexualidade opostas à heteronormatividade); brasileiros - estrangeiros; não deficientes - pessoas com deficiências. Há sempre um polo privilegiado (norma) e um polo em situação oposta (diverso) revelando uma organização hierárquica que não desaparece quando os sujeitos da diversidade são incluídos, pois a inclusão se dá, como observam Bentes e Hayashi (2016), no universo inerente à norma cabendo aos incluídos, adaptar-se.

A problematização da inclusão dos sujeitos da diversidade não deve ser lida como defesa da não inclusão destes sujeitos na escola. Problematizo não para apresentar soluções e/ou respostas supostamente melhores, mas para interrogar os regimes de verdade estabelecidos (FOUCAULT, 2004) sobre a diversidade na educação. A inclusão da diversidade a normaliza ao incluí-la nos moldes da lógica normativa a qual ela é "estranha" e deve se adequar. Como escreve Lins (2005), e como inferi na maioria dos trabalhos, o sistema de referência não é posto em causa, de modo que a inclusão nestes moldes pode ser entendida como concessão benevolente da norma. A diversidade é incluída e tolerada, pois "o que é simplesmente tolerado, sobretudo em momentos ditos democráticos, permanece em posição de inferioridade em relação ao que é dado como norma" (LINS, 2005, p. 28). Ao tratar as diferenças como iguais, por força do princípio constitucional da isonomia, a escola assume uma referência. O que é igual, é igual à alguma coisa, a alguém. Essa "Alguma coisa", esse "alguém", é o sistema de referência ao qual Lins (2005) alude argumentando que não é posto em causa. Afirmação corroborada pelos resultados deste estudo. A norma não precisa ser incluída, tolerada, ter seu acesso e permanência garantidos, pois ela é a expressão privilegiada. É o sistema de referência, o epicentro produtor das identidades desviantes que chamamos diversidade e convidamos a se sentar à mesa como iguais. É aqui que reside a sutileza da captura identitária. Reduzir a diferença pura a igualdade é matá-la a golpes identitários que sobrecodificam e normalizam a multiplicidade expropriando sua potência de vida. Penso que argumentar em favor dos direitos dos sujeitos diversos na contemporaneidade é fundamental para evitar que essas pessoas sofram violências e exclusões. Porém, é importante também interrogar as normas a partir das quais o diverso é produzido como diverso (DELEUZE, 2018). Enquanto o sistema de referência não for posto em causa, como sugere Lins (2005), a hierarquia engendrada pelo agenciamento binário "norma - anomia" não desaparecerá.

\section{REFERÊNCIAS}

1. ABRAMOWICZ, Anete; DA CRUZ, Ana Cristina Juvenal; RODRIGUES, Tatiane Cosentino. A diferença e a diversidade na educação. Revista Semestral do Departamento e do Programa de Pós-Graduação em Sociologia da UFSCar, v. 1, n. 2, 2011. 
2. ABU-EL-HAJ, Mônica Farias; FIALHO, Lia Machado Fiuza. Formação docente e práticas pedagógicas multiculturais críticas. Revista Educação em Questão, v. 57, n. 53, 2019. DOI: https://doi.org/10.21680/1981-1802.2019v57n53ID17109.

3. ARÉVALO, Amaral Palevi Gómez. El armario está abierto? estudios sobre diversidad sexual en El Salvador. Educação \& Realidade, v. 42, n. 4, p. 1375-1397, 2017. DOI: http://dx.doi.org/10.1590/2175-623662013.

4. $\quad$ BARDIN, Laurence. Análise de conteúdo. Lisboa: Edições 70. 1977.

5. BENTES, José Anchieta de Oliveira; HAYASHI, Maria Cristina Piumbato Innocentini. Normalidade, diversidade e alteridade na história do Instituto Nacional de Surdos. Revista Brasileira de Educação, v. 21, n. 67, p. 851-874, 2016. DOI: https://doi.org/10.1590/S1413-24782016216744.

6. BORGES, Rúbia Aparecida Cidade. Na cama com Procusto: contemplando os diferentes no currículo de Geografia. Currículo sem Fronteiras, v. 19, n. 1, p. 245-277, 2019.

7. BRASIL. Constituição Federal de 1988. Promulgada em 5 de outubro de 1988. Diário Oficial [da] União, Poder Executivo, Brasília, DF, 5 out. 1988.

8. $\quad$ BRASIL. Lei 11.645. Brasília: Ministério da Educação, 2008.

9. $\quad$ BRASIL. Lei 10.639. Brasília: Ministério da Educação, 2003.

10. BRASIL. Secretaria de Educação Fundamental. Parâmetros curriculares nacionais: apresentação dos temas transversais, ética/Secretaria de Educação Fundamental. Brasília: MEC/SEF, 1997.

11. BRASIL. Lei n 9.394. Estabelece as Diretrizes e Bases da educação Nacional. Diário Oficial [da] União, Poder Executivo, Brasília, DF, 23 dez. 1996.

12. BRITO, Eliana Póvoas Pereira Estrela. O currículo do ensino médio baiano: entre a formação integral e a valorização das diferenças. Currículo sem Fronteiras, v. 18, n. 3, p. 1003-1024, 2018.

13. CARREIRA, Denise. A execução orçamentária das políticas de diversidade nos governos Lula e Dilma: obstáculos e desafios. Revista Brasileira de Educação, v. 24, 2019. DOI: https://doi.org/10.1590/s1413-4782019240010.

14. COSTA, Joacir Marques da; DALLA CORTE, Marilene Gabriel; DA SILVA, Luciana Guilhermano. Diversidade e in/exclusão: Vozes e silêncios na formação do/a pedagogo/a. Revista e-Curriculum, v. 16, n. 3, p. 668-693, 2018. DOI http://dx.doi.org/10.23925/1809-3876.2018v16i3p668-693. 
15. DELEUZE, Gilles; PARNET, Claire. Diálogos. Trad. Eloisa Araújo Ribeiro, São Paulo: Escuta, 1998. a desnaturalização da orfandade educativa na diversidade. Revista e-Curriculum, v. 16, n. 4, 2018. DOI: https://doi.org/10.23925/1809-3876.2018v16i4p1485-1511.

21. FOUCAULT, Michel. Ética, sexualidade, política. Organização e seleção de textos Manoel Barros da Motta; tradução Elisa Monteiro, Inês Autran Dourado Barbosa. Rio de Janeiro: Forense Universitária, 2004.

22. FURLAN, Cássia Cristina; MÜLLER, Verônica Regina. O brincar e as relações de gênero: reflexões de crianças e docentes. Educação (UFSM), v. 40, n. 3, p. 711-722, 2015. DOI: https://doi.org/10.5902/1984644413728.

23. GARCÍA, Manuel Delgado; PRIETO, Francisco Javier García. La atencion a la diversidad en el sur de España: concepciones y práctica del pedagogo terapeuta. Educação, v. 42, n. 1, p. 15-32, 2017. DOI: https://doi.org/10.5902/1984644425247.

24. GIL, Antônio Carlos. Como elaborar projetos de pesquisa. - 4. ed. - São Paulo: Atlas, 2002.

GOMES, Arilson dos Santos. Africanidades e diversidades no ensino de História: entre saberes e práticas. Educar em Revista, n. 64, p. 189-214, 2017. DOI: http://dx.doi.org/10.1590/01044060.48996. 
GRAUPE, Mareli Eliane; LINS, Clecí Terezinha Lima de. Gênero e diversidade sexual: homofobia no contexto escolar. Revista UNIPLAC, v. 5, n. 1, 2017. DOI: https://doi.org/10.5902/1984644427530.

28. LINS, Daniel. Tolerância ou imagem do pensamento? In: OLIVEIRA, Salete; PASSETTI, Edson (Orgs.). A tolerância e o intempestivo. Cotia: Ateliê Editorial, 2005.

29. LÓPEZ, Nestor. Adolescentes en las aulas: la irrupción de la diferencia y el fin de la expansión educativa. Educação \& Sociedade, Campinas, v. 33, n. 120, 2012. DOI: http://dx.doi.org/10.1590/S0101-73302012000300012.

30. MÉNDEZ-TAPIA, Manuel. Reflexiones críticas sobre homofobia, educación y diversidad sexual. Educação \& Realidade, v. 42, n. 2, p. 673-686, 2017. DOI: https://doi.org/10.1590/2175-623656193.

31. MWEWA, Christian Muleka et al. Implicações étnicas e práticas pedagógicas na educação infantil em três lagoas, MS. Imagens da Educação, v. 7, n. 3, p. 86, 2017. DOI: https://doi.org/10.4025/imagenseduc.v7i3.38289.

32. OLIVEIRA JÚNIOR, Isaias Batista de; MAIO, Eliane Rose. Diversidade sexual e homofobia: a cultura do "desagendamento" nas políticas públicas educacionais. Práxis Educativa, v. 10, n. 1, p. 35-53, 2015. DOI: 10.5212/PraxEduc.v.10i1.0002.

33. OLIVEIRA JÚNIOR, Isaias Batista de; MAIO, Eliane Rose. Não veja, ouça ou fale: Zarus presentes nos discursos docentes sobre diversidade sexual e homofobia. Educação, v. 42, n. 1, p. 96-106, 2019. DOI: 10.15448/1981-2582.2019.1.2990.

34. PARAÍSO, Marlucy Alves. Pesquisas pós-críticas em educação no Brasil: esboço de um mapa. Cadernos de pesquisa, v. 34, n. 122, p. 283-303, 2004.

35. PARAísO, Marlucy Alves. O currículo entre a busca por "bom desempenho" e a garantia das diferenças. In: DALBEN, Ângela; DINIZ, Júlio; LEAL, Leiva e SANTOS, Lucíola (Orgs.). Convergências e tensões no campo da formação e do trabalho docente: currículo, ensino de educação física; ensino de geografia; ensino de história; escola, família e comunidade. Belo Horizonte: Autêntica, 2010.

PEREIRA, Andressa Silva; DAMASCENO, Alan Rocha. Pedagogia: para quê? Desafios contemporâneos à formação para afirmação da diversidade humana. Educação, v. 40, n. 1, 2017. DOI: http://dx.doi.org/10.15448/1981-2582.2017.1.24299. 
37. RUSSO, Kelly; PALADINO, Mariana. A lei n. 11.645 e a visão dos professores do Rio de Janeiro sobre a temática indígena na escola. Revista Brasileira de Educação, v. 21, n. 67, p. 897-921, 2016. DOI: http://dx.doi.org/10.1590/S1413-24782016216746.

SANT'ANNA, Paulo Afranio; MARQUES, Luiz Otávio Costa. Pibid Diversidade e a formação de educadores do campo. Educação \& Realidade, v. 40, n. 3, p. 725-744, 2015. DOI: https://doi.org/10.1590/2175-623645795.

SILVA, Mário Medeiros da; PAES, Vanderleia. Diversidade sociocultural e desempenho escolar: um olhar sobre o currículo em ação. Revista e-Curriculum, v. 12, n. 3, p. 2192-2210, 2014.

SILVA, Régis Henrique dos Reis; GAMBOA, Silvio Ancisar Sanchez. Do esquema paradigmático à matriz epistemológica: sistematizando novos níveis de análise. ETD - Educação Temática Digital, v. 16, n. 1, p. 48-66, 2014. DOI: https://doi.org/10.20396/etd.v16i1.1329.

41. SOUZA, Elaine de Jesus; DA SILVA, Joilson Pereira; SANTOS, Claudiene. Diversidade sexual e homofobia na escola:(des) conhecimento e vivências de docentes. Revista Educação em Questão, v. 54, n. 41, p. 111-138, 2016. DOI: 10.21680/1981-1802.2016v54n41ID10160.

42. SOUSA, A. G. M; LIMA, A. S. Diversidade étnica na educação infantil: minimizando desigualdades ou difundindo estereótipos? Imagens da Educação, v. 7, n. 2, p. 64-75, 2017. DOI: http://doi.org/10.4025/imagenseduc.v7i2.34197.

43. TEIXEIRA, Pedro Pinheiro. As relações entre diversidade e a discussão de temas controversos: Desafios atuais para a escola. Revista e-Curriculum, v. 16, n. 2, p. 494-515, 2018. DOI: https://doi.org/10.23925/1809-3876.2018v16i2p494-515.

44. TRUJILLO, Gracia. Pensar desde otro lugar, pensar lo impensable: hacia una pedagogía queer. Educação e pesquisa, v. 41, p. 1527-1540, 2015. DOI: https://doi.org/10.1590/S15179702201508142550.

45. VALDERRAMA, Caterine Galaz; MELIS, Rolando Poblete. Políticas públicas educativas y las sexualidades en Chile post-dictadura: opacidades e hiper-visibilidades de sujetos LGTBI. Educar em Revista, v. 35, n. 74, p. 251-269, 2019. DOI: 10.1590/0104-4060.62610.

46. VARGAS, Felipe Jiménez; SANHUEZA, Carmen Montecinos. Diversidad, modelos de gestión y formación inicial docente: Desafíos formativos desde una perspectiva de justicia social. Revista Brasileira de Educação, v. 23, 2018. DOI: https://doi.org/10.1590/s1413-24782018230005. 
47. VIANNA, Cláudia Pereira. O movimento LGBT e as políticas de educação de gênero e diversidade sexual: perdas, ganhos e desafios. Educação e Pesquisa, v. 41, n. 3, p. 791-806, 2015. DOI: https://doi.org/10.1590/s1517-97022015031914.

\section{Amarildo Inácio dos Santos}

Doutorando pelo Programa de Pós-Graduação em Educação da Universidade Federal da Bahia (PPGED-UFBA). Mestre em Educação pelo Programa de Pós-Graduação em Educação da Universidade Regional de Blumenau (PPGE-FURB). Licenciado em Música pela Universidade Regional de Blumenau (FURB). Licenciando em Pedagogia (2019 - 2023) e Pós-graduando em Gestão Escolar e Coordenação Pedagógica (2020 - 2021) pela Faculdade Unyleya. Integrante do Grupo de Pesquisa Políticas de Educação na Contemporaneidade (FURB). Foi bolsista ID do PIBID no Subprojeto Gestão Escolar Democrática (2014-2016). Foi professor de Artes/Música nas Redes Estadual de Ensino de Santa Catarina e Redes Municipais de Ensino de Blumenau-SC e Brusque-SC. Atualmente desenvolve pesquisas relacionadas às temáticas escola, currículo, educação, diferenças e produção de subjetividades na contemporaneidade neoliberal.

\section{Como citar este documento:}

SANTOS, Amarildo Inácio dos. ABORDAGENS EPISTEMOLÓGICAS DA DIVERSIDADE E SUJEITOS REPRESENTADOS EM PESQUISAS. Reflexão e Ação, Santa Cruz do Sul, v. 29, n. 1, p. 34-49, jan. 2021. ISSN 1982-9949. Acesso em:_. doi: http://dx.doi.org/10.17058/rea.v29i1.15401 